\title{
Boa Companhia e a composição de Primus: "encontros" que geram procedimentos criativos
}

\author{
Daves OTANI ${ }^{1}$ \\ Escola Superior de Artes Célia Helena - ESCH
}

A proposta deste artigo é falar sobre como podemos encontrar, em decorrência de uma atitude ativa, embora com contornos casuais, recursos que nos auxiliem na montagem e manutenção de uma obra teatral. O texto está voltado também a mostrar que a obra teatral, em um contexto de grupo de repertório, acaba sendo marcada pela história do grupo, e pelos encontros gerados a partir desta história. Para isso contarei um pouco sobre a Boa Companhia e o espetáculo Primus, sua origem ligada à Universidade Estadual de Campinas e as especificidades que geraram diferentes possibilidades de relações artísticas.

No final de meu primeiro ano da graduação em Artes Cênicas na Unicamp fui convidado, como aluno da turma de 1992, a participar de um exercício cênico sobre o ciúme, inspirado em Otelo, o mouro de Veneza, de William Shakespeare, uma proposta da professora da disciplina Dança, música e ritmo II, Verônica Fabrini. Eis o ato gerador da Boa Companhia, grupo de pesquisa cênica no qual atuo desde então e a partir de onde desenvolvo minha pesquisa sobre improvisação como recurso criativo, tanto como ator quanto como educador na graduação em teatro da Escola Superior de Artes Célia Helena (ESCH São Paulo). Posso dizer que o aprendizado destes quase vinte anos de atuação, quinze como ator profissional e mais de dez anos como professor em diferentes níveis, carrega o espírito que vem da Universidade, ligado a uma pesquisa extracurricular, e foi construído sobre uma prática da cena, influenciado pela dança e pela música em um ritmo de experimentação. Esse aprendizado foi alicerçado na Boa Companhia, dirigida artisticamente pela Prof. ${ }^{a}$ Dra. Verônica Fabrini. No grupo estão comigo, desde sua formação, Eduardo Osorio, Moacir Ferraz e Alexandre Caetano; nesses anos fiz com eles mais de dezessete peças teatrais. Embora em constante diálogo com pesquisas afins, este artigo é determinado por meu ponto de vista singular. A solidão e a comunhão no fazer teatral são opostos complementares; ser só, ser junto. Para mim, uma característica fundamental da atuação teatral é a de estar atento à ação individual no corpo coletivo.

\footnotetext{
${ }^{1}$ Ator da Boa Companhia desde 1992. É Mestre (2005) e Doutor (2012) em Artes pela Unicamp, e professor da Escola Superior de Artes Célia Helena (São Paulo), onde leciona Interpretação, Improvisação e Jogos e pedagogia teatral, além de ser coordenador do curso de Pós-graduação lato sensu em direção teatral. E-mail: davesotani@yahoo.com.br.
} 
Para exemplificar o que chamo de recurso criativo, ou matriz criativa ${ }^{2}$, escolhi o papel da capoeira na montagem do espetáculo Primus (adaptação do conto Comunicado a uma academia, de Franz Kafka), montado pela Boa Companhia em 1999. Verônica Fabrini de Almeida assina a adaptação e a direção da peça, que completou treze anos em 2012 e até hoje conta com o mesmo elenco: os já citados integrantes do grupo. Nesses doze anos ininterruptos de apresentações, Primus foi apresentado em mais de dez estados brasileiros e em mais de cinquenta cidades em território nacional. No exterior (Alemanha - Berlim e Erlangen -, Rússia, Portugal e Marrocos) foi feita em versões trilíngues: português, inglês e a língua local de cada lugar. A peça gerou ainda um documento importante, um caderno em comemoração aos dez anos do espetáculo, com artigos de colaboradores, críticos e criadores do espetáculo, produzido em 2009 pela Associação Cultural Boa Companhia ${ }^{3}$, com o apoio da Caixa Cultural. Tal histórico me leva constantemente a perguntar sobre sua potência de sobrevivência e de transformação. Levou-me, ainda, a um mestrado e um doutorado que o utilizam como material de reflexão ${ }^{4}$. As questões da minha pesquisa acadêmica se referem aos procedimentos criativos ligados à improvisação e ao seu papel como elemento estruturante do espetáculo, tanto do ponto de vista da criação, como da manutenção da obra. São questões que busco compartilhar no presente artigo.

A peça Primus leva para o palco a comunicação de Pedro, o vermelho, a uma academia de cientistas, relatando seu processo de transformação: de um macaco capturado na selva para um astro do teatro de variedades. O espetáculo se estrutura a partir dessa história, a princípio, absurda - um macaco que se torna homem por meio de uma capacidade descomunal de adaptação e de uma obstinação e treinamento árduos. Penso que a extrema maestria literária de Kafka lega, à história absurda, grande força. A Boa Companhia busca trazer para a cena, valendo-se tanto da força literária quanto do imaginário da obra, as contradições do homem em conflito com sua origem animal, bem como as tensões entre liberdade, necessidade e prisão. Franz Kafka é um exímio construtor de imagens impactantes, assustadoras e, sobretudo, intrigantes e dotadas de um potencial imenso de inspiração para cena: "o que ele traduz em imagens não são conceitos, mas

\footnotetext{
${ }^{2}$ Matrizes criativas são elementos que apoiam as improvisações. Podem ser mais ligadas à corporeidade (a construção do corpo ficcional propriamente dito, individual) ou mais ligadas à linguagem (ligadas às composições coletivas e relativas ao desenvolvimento do espetáculo como um todo). Aqui utilizarei o exemplo da matriz capoeira, classificada como uma matriz criativa de linguagem. A matriz criativa dá suporte à criação, fornecendo possibilidades dos atores, por meio delas, abordarem o texto escrito de forma prática.

3 A Associação Cultural Boa Companhia é a pessoa jurídica que mantém a Boa Companhia.

4 Primus é objeto de estudo da Dissertação de Mestrado $O$ ator em jogo, orientada pelo Prof. Dr. Márcio Aurélio Pires de Almeida, defendida em 2005, no Instituto de Artes da Unicamp. A peça é também objeto de estudo da Tese de Doutorado, sob orientação do Prof. Dr. Eusébio Lôbo da Silva e da Prof. ${ }^{a}$ Dra. Verônica Fabrini Machado de Almeida, intitulada Geratriz improvisacional espetacular: processo criativo da Boa Companbia, defendida em 2012 no mesmo instituto.
} 
situações" (ANDERS, 1993, p. 40). Pode-se dizer, como Günter Anders, que: "Ele não inventa imagens: assume-as. $O$ que há de sensorial nessas imagens, ele põe sob o microscópio - e veja, a metáfora mostra detalhes tão colossais que, daí em diante, a descrição adquire algo de pavorosa realidade” (Idem, ibidem). Essa construção de situações é extremamente saborosa e frutífera para a transposição ao universo teatral, e gera, ainda, muitas possibilidades de utilizações de diferentes recursos criativos, ou matrizes criativas. Posso dizer que a literatura de Kafka, por meio do conto, foi uma matriz criativa primordial que gerou, de forma contundente, outras matrizes criativas que fomentaram uma prática teatral instigante.

$\mathrm{Na}$ narrativa, Pedro, o personagem central, conta a uma plateia de acadêmicos pois é convidado a falar sobre seu processo de amestramento para a Academia - como, de macaco selvagem, foi amestrado e se transforma em um sucesso de público e crítica. Pedro relata como foi capturado na selva da Costa do Ouro, na África, e levado de navio até a Europa para ser vendido ao zoológico ou para ser encaminhado ao teatro de variedades. Pedro descreve a essa plateia que, durante a viagem, no contato com os rudes homens trabalhadores do navio, percebeu como seria fácil imitá-los: aprendeu a beber e a cuspir, e tornou-se, desde lá, um macaco destacado. A narrativa do conto é praticamente a mesma da peça, sendo que alguns trechos originais do conto são subtraídos pois são traduzidos em cena pelos recursos próprios da linguagem teatral. Pedro revela que percebeu - ainda dentro da lógica de macaco -, durante sua viagem, que por meio de sua imitação poderia viver no mundo dos homens, conquistando um lugar entre eles e livrando-se do cativeiro do zoológico. Assim o fez, pois, enquanto exímio imitador dos homens, aproxima-se deles e mostra ser mais forte como potencial atração de circo que como atração de zoológico. Ao chegar ao continente, por meio de uma árdua etapa de aprendizado, extrapola sua condição de bicho preso e é encaminhado ao "teatro de variedades". Então se torna um astro, e é convidado a relatar seus cinco anos de transformação à Academia.

Primus é uma leitura do conto de Kafka a partir da vivência do corpo. A peça foi montada a partir de improvisações balizadas em determinadas matrizes criativas: capoeira, percussão africana, sapateado, canto popular e lírico, acrobacias e primatologia (área da etologia que estuda os primatas). Cada matriz criativa chegou ao processo por um caminho próprio. Aqui, buscando exemplificar, falarei mais detalhadamente de como a capoeira chegou ao processo, por sua ligação com o curso de Artes Cênicas da Unicamp e com minha própria história (comunhão, solidão, do coletivo ao indivíduo). A capoeira me levou 
a aprender e evoluir na utilização da improvisação como recurso criativo, a olhar mais profundamente e a melhor construir meu ofício e o modo de me relacionar com ele.

Quando nascia Primus, a ideia de processo de grupo-colaborativo levava o pensamento do ator criador a uma radicalidade muito grande; o ator é, nesse contexto, também pensador e construtor da cena, em parceria com a direção do espetáculo:

Utilizando-se de vários materiais, o ator poderá selecioná-los a partir de percepções resultantes de uma experiência prática. Ele deverá ser capaz de perceber quais os materiais adequados, que produzem "sentido" a partir de suas ações (BONFITTO, 2006, pp. 140-1).

A capoeira me permitiu "perceber quais os materiais adequados, que produzem ‘sentido' a partir de suas (minhas) ações”, por meio de seu jogo e de sua prática.

A peça foi montada em 1999, quatro anos após a saída dos atores do curso de graduação. Foi um tempo que evidenciou aos integrantes da companhia as dificuldades do mundo fora da Universidade, que permitiu o confronto com o universo desprotegido dos vínculos formais com a academia. A intuição parece ser um elemento fundamental na escolha desse conto como desafio ao momento do grupo, visto que o conto problematiza o próprio fazer artístico, dialogando com o momento pelo qual passávamos. Intuitivamente, o grupo se colocou no desafio de questionar a sua arte por meio de Kafka. Apenas imitar não é único caminho, o artista pode escolher outras maneiras de evoluir artisticamente. $\mathrm{Na}$ reestruturação pela qual o grupo passava, questionar-se enquanto coletivo foi imprescindível. Mas essa opção não foi racionalmente definida: o conto “caiu nas mãos” do grupo, que aceitou o acaso e concretizou os questionamentos na peça.

Como venho observando, quando se trata de processos criativos, determinados acasos se dão e os percursos se delineiam em momentos cruciais, as escolhas feitas nos conduzem por trilhas a princípio indecifráveis, mas que ao final do percurso revelam justa clareza. Componente fundamental da origem do espetáculo aqui estudado é o acaso; a Boa Companhia aceita trabalhar com este aspecto e faz dele uma possibilidade de geração de materiais. Segunda a diretora Verônica Fabrini, para o trabalho da companhia, ouvir o acaso é uma das maneiras de trabalhar com a intuição. Não a intuição de dentro, mas uma intuição que se dá fora e da ressonância desta dentro.

Tal aspecto se relaciona aos contatos pessoais ocorridos a partir da universidade. Inserida, desde sua origem, no âmbito da academia, e dirigida por uma professora do Departamento de Artes Cênicas da Unicamp, o encontro de diversos profissionais com a companhia ocorre frequentemente e a diretora traz pessoas para colaborar no trabalho e as 
tornam participantes efetivas do processo. Esse trânsito de informações e experiências gera encontros com diferentes formas de atuar artisticamente, formas essas que produzem novas possibilidades de materializar a cena. Não são encontros marcados, são casualidades advindas da natureza da universidade e da postura da companhia e da diretora. Evidentemente que essa postura está vinculada a um olhar seletivo, em que aceitar significa estar em consonância com o texto de cada montagem, e, posteriormente, com o resultado cênico da prática sobre ele.

A questão da imitação do macaco é um exemplo. Era preciso na montagem, de alguma maneira, imitar o macaco, pois nós atores seríamos, enquanto personagens, exmacacos que conquistaram um lugar no mundo dos homens. Pedro, o personagem central do conto, é considerado um vitorioso pelo uso desta ferramenta: a imitação. Fazer o caminho inverso de Pedro, homens imitando macacos, era, ao nosso olhar de criadores da cena, fundamental no trato cênico com o conto. Como imitar um macaco sem recorrer a uma mimese formal, calcada apenas nos recursos básicos da forma exterior? Como escapar do estereótipo? Não interessava à Boa Companhia apenas uma imitação. Interessava transgredir também a forma macaco, apropriando-se dela em busca de um conteúdo que invadisse o terreno do simbólico, pois para nós Kafka não pensava em discutir e nem em investigar a origem do homem, procurava criar um jogo a partir do homem e sua possível origem. Nesse sentido, uma aproximação bem humorada parecia igualmente pertinente.

O conto soava, para nós, muito irônico e dotado de um senso de humor perspicaz sobre o ser humano; a montagem é conduzida por essa leitura bem humorada. Leandro Konder observa esse aspecto na obra de Kafka:

O senso de humor de Kafka é um elemento importante de sua maneira de encarar a vida e desempenha um papel notável na sua obra. (...) O senso de humor era justamente uma das forças que Kafka possuía para mobilizar e renovar as suas esperanças, para tornar mais ativo o seu profundo inconformismo (KONDER, 1967, p. 119).

E, ainda:

Sabemos por Max Brod que, quando Kafka lia para seus mais íntimos algumas das suas histórias, os amigos "estouravam de rir". Segundo Brod, a cena inicial do romance $O$ Processo - a cena em que o personagem central é detido em seu quarto por dois investigadores de polícia em virtude de uma acusação que não lhe dizem qual seja - provocou gargalhadas quando lida para os íntimos: 'todos foram tomados de um irresistível acesso de riso e o próprio Kafka ria tanto que, por alguns instantes, não pode continuar a leitura' (Idem, p. 123). 
O conto emana, ao lado da ironia, crueldade com o ser humano, e a montagem evoca também crueldade. Olhar para Kafka apenas como um autor soturno seria, na nossa visão de criadores de Primus, um equívoco. É também na perspectiva engraçada do universo de Kafka que Primus trabalha e onde, olhando para ele após tantos anos, parece residir muito do poder deste espetáculo. Os espectadores descobrem a crueldade através do humor, e a resposta do público vem dessa ambiguidade da montagem: é cruel e é bem humorada; o público ri de si mesmo e se assombra com o mundo do qual participa. O riso funciona no plano da crítica ao homem, estrutura-se na falha. Nas palavras de Bergson:

Não há comicidade fora daquilo que é propriamente humano [...] Rimos de um animal, mas por ter surpreendido nele uma atitude humana ou uma expressão humana [...] Cabe ressaltar agora, como sintoma não menos digno de nota, a insensibilidade que ordinariamente acompanha o riso (BERGSON, 2007, pp. 2-3).

Essa insensibilidade a que se refere Bergson é o que chamo de crueldade, um olhar para o homem sem comoção, como diz o autor sobre o riso: “A indiferença é seu meio natural" (BERGSON, 2007, p. 3). Um olhar para o homem sem desvesti-lo de suas falhas. Ironia e crueldade. Como levar para a cena as forças dessa junção? Quando conheci a capoeira na graduação, havia percebido essa dupla força no jogo dançado.

Quando nós, da Boa Companhia, trabalhamos na graduação em Artes Cênicas da Unicamp, em 1992, com o professor Eusébio Lôbo, a linguagem da capoeira como recurso ao treinamento do ator, fizemos em um ambiente específico, o universitário. Dessa vivência, no entanto, participaram todos os atores da Boa Companhia, então alunos da graduação e da professora Verônica Fabrini. Nossa opção em manter o trabalho artístico em Barão Geraldo, distrito de Campinas onde está sediada a Unicamp, estimulou o uso da capoeira como matriz criativa para a montagem do espetáculo. Essa possibilidade se deu como fruto do contato com a universidade, tanto em relação à proximidade, quanto como na manutenção de uma pesquisa acadêmica da diretora e dos atores do grupo, que permaneceram realizando trabalhos no Departamento de Artes Cênicas, direcionando mestrados e doutorados ligados à pesquisa do grupo.

A capoeira, desenvolvida no Departamento de Artes Cênicas da Unicamp, através de um trabalho implantado, desde os anos 90, por Eusébio Lôbo (Professor titular aposentado do Departamento de Dança da mesma universidade e um dos pioneiros do estudo da dança no âmbito acadêmico no Brasil) foi apresentada aos alunos em 1992. O trabalho implantado pelo professor Eusébio permitiu que no ano da montagem estivesse se desenvolvendo um treinamento de capoeira no Departamento de Artes Cênicas, em outro 
molde. Eusébio ministrava,em 1992, disciplina curricular que trabalhava diretamente a capoeira como elemento de treinamento ao ator; já em 1999, esse trabalho era um treinamento livre, abertos a alunos de outros departamentos e também uma disciplina eletiva aos alunos da graduação em Artes Cênicas. Foi Verônica Fabrini, então coordenadora da graduação, quem estimulou o Monitor Jacinto Rodrigues ${ }^{5}$ - professor de capoeira - a manter o treinamento continuado de capoeira em forma de aulas livres e também como aulas regulares eletivas. A partir dessa contiguidade, Verônica chamou o professor Jacinto para trabalhar conosco no processo de aproximação com essa linguagem na criação do espetáculo Primus. Apenas em virtude de uma "convivência" de anos com a capoeira, construída desde a graduação e ligada à universidade e ao seu entorno é que pudemos gerar a ideia de estímulo à peça, de uma maneira singular que ia além da ideia de treinamento. O "encontro casual” com Eusébio Lobo e, posteriormente, com Jacinto Rodrigues, acabou por trazer a capoeira até Primus. De alguma forma a capoeira já pairava sobre a Boa Companhia desde a graduação. Nós, integrantes do grupo, continuamos a trabalhar juntos e, sete anos depois, já profissionais da área, voltamos a estabelecer contato com a capoeira e a experimentá-la como recurso criativo ao espetáculo.

A capoeira angola nos pareceu, na conjuntura da montagem de Primus, um recurso de aproximação com o universo do macaco muito pertinente, embora não houvesse esse raciocínio lógico da ironia e da crueldade que ela, a meu ver, contém. A capoeira, no entanto, apontava para a necessidade de simbologia que o grupo procurava, já que ela "traz em sua movimentação básica uma gama diversificada de estilo de luta de animais, chegando a incorporar os nomes destes para descrever determinados movimentos, como [...] o saltodo-macaco etc" (SILVA, 2008, p. 58). O jogador-lutador parece adquirir uma “destreza animal" no jogo da capoeira, embora não busque imitar animais. A capoeira é uma linguagem dançada que dialoga com a essência do espetáculo Primus, uma linguagem corporal extremamente simbólica e rítmica, de uma fisicalidade radical e com conotações bélicas, como afirma Eusébio Lobo da Silva:

Todavia a hipótese de que a gênese da capoeira está nas danças, as quais têm como base a interpretação dos combates dos animais, aponta para uma matériaprima de caráter híbrido, o que a distancia da ideia de que a capoeira foi criada com o propósito de disfarçar-se em dança. Ela é dança-luta porque sua origem mimética incorporou a própria luta que os animais travavam; sua conotação bélica deve-se

\footnotetext{
${ }^{5}$ Jacinto Rodrigues é funcionário da Unicamp, trabalhou muitos anos em diversos setores da universidade e, em meados de 1999, foi transferido para o Departamento de Artes Cênicas, onde se tornou monitor pedagógico.
} 
provavelmente à força das circunstâncias históricas da escravidão no Brasil (SILVA, 2008, p. 58)

Acredito que a própria escolha da capoeira como matriz para a montagem, proposta que partiu da diretora, advém dessa radicalidade física, que coincide com as opções estéticas da companhia, associada à montagem e às suas demandas, como por exemplo, a "luta" de Pedro pela sobrevivência fora da jaula. A Boa Companhia parte do trabalho do ator na sua criação, e seu princípio norteador é o ator em ação sustentado pela música e pelo coro, pela coletividade que age sobre o tema por meio do jogo. Nesse sentido, antes de o texto ser proferido, antes de a história ser contada, estão os conflitos dos corpos, em uníssono ou em oposição, os riscos dos movimentos acelerados, as suspensões do tempo, a ocupação a princípio desenfreada do espaço, aspectos marcadamente trabalhados no jogo da capoeira. A dança-jogo sugere a ideia de um "empurrão" do capoeirista (o jogador-dançarino) na roda, para nada restar a ele senão jogar; é um princípio similar ao contexto do conto. Seria como a situação do personagem Pedro no navio: empurrado ao desconhecido, parte em busca de uma saída e joga com sua condição, tirando da situação o melhor proveito, de acordo com seu interesse: preservar-se. O jogador de capoeira busca diversão, mas é um lutador. E ainda que brinque, também ataca e defende, embora pretenda, sobretudo, sair ileso. Acrescente-se a isso o fato de a capoeira permitir o aprimoramento da ideia de prontidão no jogo, prontidão ligada ao aspecto criativo dentro de uma estrutura pré-definida, o que possibilita o encontro de um modo próprio de agir do jogador, como diz Waldeloir Rego:

Há ainda outra coisa importante no desenvolvimento da capoeira - é que dentro das limitações das regras do jogo, o capoeira tem liberdade de criar, na hora, golpes de ataque e de defesa conforme seja o caso, que nunca foram previstos e sem nome específico e que, após o jogo ele próprio não se lembra mais do tipo de expediente que improvisou. No jogo da capoeira vai muito de pessoal (REGO, 1968, p. 34).

O jogo entre indivíduo e coro/coletividade é um aspecto da capoeira muito similar ao teatro. A capoeira, quando começamos a direcionar sua prática para a montagem, nos proporcionou uma atenção cênica e um estado que cada vez mais nos conduzia à sensação

\footnotetext{
${ }^{6}$ Não cabe aqui, a meu ver, defender nenhuma hipótese definitiva sobre a origem da capoeira, apenas utilizo a afirmação do Prof. Dr. Eusébio Lobo da Silva, que compartilha a ideia de que a capoeira tem um lado imitativo dos animais, a fim de investigar essa relação criativa que se deu, já que esse aspecto foi explorado pela Boa Companhia na utilização da capoeira como matriz criativa do espetáculo. A relação criativa com a capoeira é livre e pode, a meu ver, grifar aspectos de tal recurso de acordo com a intenção da montagem, dentro do recorte da obra.
} 
de ser Pedro, o vermelho, o macaco capturado na selva, que em um esforço extremo alcança a glória de transmudar sua própria natureza. A situação de Pedro parece ser análoga a um dos atributos do capoeirista, que é o de desenvolver a capacidade de sobrevivência do ser: "A capoeira foi inventada com a finalidade de divertimento, mas na realidade funcionava como faca de dois gumes. Ao lado do normal e do cotidiano, que era divertir, era luta também no momento oportuno (REGO, 1968, p. 35). É preciso frisar o fato de que esta utilização da capoeira é um recorte do grupo na criação da estrutura cênica da peça, como matriz criativa, usada, portanto, para um fim específico e com certa liberdade que envolve muito mais uma aproximação prática do que um conhecimento teórico sobre a capoeira, guardando uma limitação na utilização dos recursos plenos e da vastidão da capoeira, mesmo no sentido prático. O mesmo processo se dá na utilização de outras matrizes criativas (percussão africana, primatologia, sapateado, canto popular e lírico), pois as matrizes criativas são "combustíveis" para o fazer teatral, e não objetos de estudos em si mesmos.

O treinamento com a capoeira se dava na nossa sede, o Útero de Vênus, onde o grupo realizava constantes treinamentos e cursos de aperfeiçoamento, e onde o grupo buscava uma identidade própria, inclusive no sentido de sedimentar seu espaço físico próprio. Primus tem muito da proximidade com a casa da Boa Companhia, do investimento do grupo na sua autonomia. Tanto no âmbito material quanto simbólico, a montagem do espetáculo foi como um mergulho no lugar da origem, no espaço próprio, na procura da própria imagem. A capoeira estabeleceu uma ação de aceitação - por meio da ação do jogo, por meio do esforço dos atores em se educarem no exercício do macaco -, das tensões oriundas da atitude de jogar o jogo do imprevisto. Estimulou que nós, atores, admitíssemos o homem enquanto mistura de saber e instinto, incitou que aceitássemos experimentar ser bicho homem? ${ }^{7}$.

De forma igualmente "casual", se deram nossas incursões a outras matrizes criativas do espetáculo, por meio de "encontros". No campo do comportamento e da primatologia, a irmã da diretora, M. Isabel Almeida acabara de concluir o mestrado na psicologia experimental/etologia e, em diversos encontros, compartilhava conosco suas descobertas, seu entusiasmo, seus registros de campo e sua bibliografia. Já para nos aproximarmos do teatro de variedades, a "saída" encontrada pelo personagem do conto para fugir do zoológico, contamos com a colaboração de Célia Froufe, na época aluna do curso de dança da Unicamp. Célia dominava bem o sapateado americano e, a partir da ideia de Verônica

\footnotetext{
${ }^{7}$ Para maiores informações, ver OTANI (2005).
} 
Fabrini de fazer do sapateado uma metáfora da extrema habilidade que adquire o personagem na obtenção de técnicas variadas, chamamos Célia para nos auxiliar nesses estudos e montar a coreografia de sapateado que é realizada na peça. No campo da voz, o cantor Max Costa, recém-formado no curso de música da Unicamp, nos fez trilhar o longo caminho vocal, da fala ao canto popular, do canto popular ao canto lírico. Dessa forma a corporeidade de Pedro, o vermelho não foi composta apenas de técnica e informações. Foi construída com a colaboração dos profissionais que encontramos, que estavam no momento da montagem, no "misterioso espaço" entre a universidade e a atuação artística profissional. Além deles, também se incluem Clermont Pithan e Isabelle Dufault, pesquisadores da dança contemporânea e do treinamento físico para a preparação do intérprete, amigos da diretora desde a graduação e, por proximidade e afinidade, parceiros da Boa Companhia até hoje. O trabalho, no entanto, acontece com a apropriação, por parte dos atores, dos elementos que resultam de tais encontros e que, em colaboração, compõem a obra. Essa forma de proceder está ligada, a meu ver, com o curso de graduação em Artes Cênicas da Unicamp:

[...] Muito mais que um intérprete de personagens, [o graduando em Artes Cênicas da Unicamp] deve aproximar-se da condição de atuador, de dançarino ou de performer. [...] adapta o texto, dirige e interpreta, além de conceber cenários e figurinos (FERNANDES, 2010, p. 202 - Observação minha).

Essa "essência artesanal" marca a origem do grupo, ecoando a formação recebida no Departamento de Artes Cênicas da Universidade de Campinas, onde o mergulho em todos os níveis da produção é parte do procedimento pedagógico do curso. A opção de manter uma sede em Barão Geraldo dialoga com essa característica. A escolha de viver de teatro em Barão Geraldo é limitada, é preciso produzir um teatro diversificado. As facilidades obtidas - como, por exemplo, a proximidade com os pesquisadores e a pluralidade de pessoas do ambiente universitário - e as condições vinculadas a uma pesquisa continuada produzem uma qualidade específica. Essas qualidades se revelam na cena segundo minha observação e experiência ao longo desses vinte anos de trabalho, além de contato com estudiosos do trabalho de grupo e da Boa Companhia que apontam suas características.

A capoeira é, portanto, apenas uma das matrizes criativas utilizadas em Primus, através do diálogo estabelecido com diferentes pessoas e diferentes referências matriciais, resultantes dos encontros proporcionados por uma espécie de acaso - que apenas ocorre 
devido a um contexto específico e a uma postura de aceitação dos acasos. A Boa Companhia busca costurar esses "encontros casuais" e deixar que seu trabalho seja por eles permeado. É como se a obra pertencesse ao mundo; e o grupo e seus artistas fossem apenas canais que proporcionam que as imagens desse mundo se materializem na cena.

\title{
REFERÊNCIAS BIBLIOGRÁFICAS:
}

ANDERS, Günter. Kafka: pró e contra. Trad. Modesto Carone. Perspectiva, São Paulo, 1993.

BÉRGSON, Henri. O riso: ensaio sobre a significação da comicidade. $2^{\mathrm{a}}$ ed. Trad. Ivone Castilho Benedetti. São Paulo, Martins Fontes, 2007, BONFITO, Matteo. O ator-compositor. São Paulo, Perspectiva, 2010.

OTANI, Daves. O ator em jogo. Dissertação (Mestrado em Artes). Campinas, Universidade Estadual de Campinas, 2005.

FERNANDES, Sílvia. Teatralidades contemporâneas. São Paulo/Perspectiva, FAPESP, 2010.

KAFKA, Franz, Contos, fábulas e aforismos. Trad. Ennio Silveira. Rio de Janeiro, Civilização brasileira, 1993.

KONDER, Leandro. Kafka - vida e obra. $2^{\mathrm{a}}$ ed. Rio de Janeiro, José Álvaro, 1967.

SILVA, Eusébio lobo da. O corpo na capoeira. Breve panorama: estórias e história da capoeira. vol. 2. Campinas, SP, Editora da Unicamp, 2008.

REGO, Waldeloir. Capoeira Angola: ensaio sócio-etnográfico. Salvador, Itapuã, 1968.

\begin{abstract}
The article talks about chance as a decisive element regarding the direction of the construction process of the play Primus, by the group Boa Companhia, as well as the company's creative attitude and how their history provides that "chance encounters" generate ways of adapting the Franz Kafka's short story ( $A$ Report to an academy), which inspired the play. As an example, the author speaks about how capoeira was used throughout the play as a result of the group's own history in the State University of Campinas (Unicamp), the history of capoeira in the Department of Performing Arts, where the group was formed, and the approach of the artistic director and the repertoire company, which add elements based on "chance encounters".
\end{abstract}

Keywords: theater group; creative matrix; capoeira. 